\title{
The Teacher Behavior Inventory: Validation of Teacher Behavior in Interactive Lecture Environment
}

\section{Word count: 6,157 (including tables, figure, and references)}

\begin{abstract}
Students' rating of teacher behaviors provides valuable information on teaching improvement and instructional quality. Unfortunately, there is lack of new validated instruments for measuring teacher behaviors. The Teacher Behaviors Inventory is an old inventory that was initially developed to measure teaching behaviors as regards lecture-based instructions, which is effected through the use of low-inference items. The aim of this study was to assess its continued suitability in the present educational setting by examining its construct validity and internal consistency through the lens of one lecturer's teaching behaviors, as rated by 527 students after six interactive lectures. The variables evaluated, as mentioned above, were achieved after an items removal process, which resulted in a 32-item version. Apart from being valid and reliable, this condensed version allows for immediate assessment of teaching behaviors after an instruction session as the rating procedure is now more straightforward and less time-consuming, and also enables a reduction in rating errors. Therefore, the 32 -item format serves as a practical diagnostic feedback tool in the present educational arena, permitting a longitudinal teaching behavior assessment to enhance teachers' professional development.
\end{abstract}

Keywords: Teaching behaviors, construct validity, internal consistency, validity, reliability 